Artigo

\title{
Avaliação Numérica da Influência da Urbanização no Regime de Convecção e nos Padrões de Precipitação da Região Metropolitana de São Paulo
}

\author{
Carolina Veiga Ferreira de Souza ${ }^{1}$, Rafael Henrique Oliveira Rangel ${ }^{2}$, Marcio Cataldi ${ }^{1}$ \\ ${ }^{1}$ Departamento de Engenharia Agrícola e do Meio Ambiente, \\ Universidade Federal Fluminense, Niterói, RJ, Brasil. \\ ${ }^{2}$ Programa de Engenharia Civil, Instituto Alberto Luiz Coimbra de Pós-Graduação e Pesquisa \\ de Engenharia, Universidade Federal do Rio de Janeiro, Rio de Janeiro, RJ, Brasil.
}

Recebido em 30 de Novembro de 2015 - Aceito em 7 de Outubro de 2016

\begin{abstract}
Resumo
Estudos indicam que regiões urbanizadas podem se tornar Ilhas de Calor Urbanas (ICU) principalmente por conta da escassez de áreas verdes, altas emissões de poluentes atmosféricos e presença de materiais civis, que absorvem e conservam mais calor por um tempo maior do que os naturais, o que faz as temperaturas desses locais serem superiores às das áreas circunvizinhas. A influência das ICU nos processos convectivos de formação da chuva de forma a modificar o regime de chuvas da região é discutida no mundo científico, já que tais processos dependem também da temperatura local. Nesse contexto, a influência da urbanização no regime de chuvas da Região Metropolitana de São Paulo (RMSP) foi avaliada por meio de métodos estatísticos e simulações numéricas. O modelo WRF foi usado no estudo com diferentes configurações de tipo e uso do solo: 1 - mancha urbana padrão do modelo; 2 - mancha urbana ampliada; 3 - mancha urbana substituída por floresta nativa. As simulações numéricas foram realizadas para eventos em que a convecção teve um papel determinante na configuração da precipitação. A análise da série histórica de precipitação demonstrou indícios de mudança de padrão de comportamento na RMSP principalmente nas décadas de 1980 e 1990 e do ano 2000 até a atualidade, apesar de não se verificar tendência de aumento ou de diminuição da precipitação média na RMSP. Os resultados das simulações ressaltaram a forte influência da urbanização na dinâmica atmosférica e, consequentemente, na ICU da RMSP, culminando em eventos severos e concentrados de precipitação convectiva ao redor e no interior da região urbanizada. Nas simulações alterando a urbanização por floresta nativa a precipitação ocorreu, na maioria das vezes, de forma mais distribuída espacialmente e com núcleos de menor intensidade.
\end{abstract}

Palavras-chave: modelo WRF; fluxos de calor na superfície; ilha de calor urbana.

\section{Numerical Evaluation of the Influence of Urbanization in the Convection and Precipitation Patterns in the Metropolitan Region of São Paulo}

\begin{abstract}
Studies indicate that urban areas can become Urban Heat Islands (UHI) mainly due to the lack of green areas, high emissions of air pollutants and presence of civil materials, which absorb and retain more heat for a longer time than natural, which makes the temperatures of these sites higher than the surrounding areas. The influence of convective processes in rain formation in order to modify the rainfall region are discussed in the scientific world, since that processes also depend on the local temperature. In this context, the influence of urbanization on rainfall in the metropolitan region of São Paulo (MRSP) was assessed by means of statistical methods and numerical simulations. The WRF model was used with different soil type and usage settings, namely: 1 - current urban sprawl; 2 - expanded urban area; 3 - urban sprawl replaced by native forest. The numerical simulations were performed for events in which convection played a key role in setting rainfall. The analysis of time series of precipitation has shown indications of change of pattern behavior in the MRSP mainly in the 1980s and 1990s and 2000 to the present, although it has not shown tendency to increase or decrease the average rainfall in the MRSP. The simulation results highlighted the strong influence of urbanization on atmospheric dynamics
\end{abstract}

Autor de correspondência: Carolina Veiga Ferreira de Souza, carolvfs@gmail.com. 
and consequently the UHI of the MRSP, culminating in severe and concentrated convective precipitation event around and inside the urban area. Simulations in which urbanization was changed to native forest, precipitation occurred, in most cases, in a more spatially distributed way and with less intensity cores.

Keywords: WRF model, heat fluxes at the surface, urban heat island.

\section{Introdução}

Nos últimos anos, a população urbana aumentou consideravelmente em todo o globo, principalmente àquelas residentes dos grandes complexos urbanos com mais de 10 milhões de habitantes, chamados pela Organização das Nações Unidas (ONU) de "megacidades". Em 1990, havia 10 megacidades em todo o mundo, passou para 28 em 2014. As maiores megacidades neste ano até então são Tóquio, Nova Deli, Xangai, Cidade do México, Mumbai e São Paulo. A expectativa é de que, em 2030, o número aumente para 41, por conta do crescimento populacional de grandes cidades da Ásia, África e América Latina (United Nations, 2014). Diversas megacidades continuam passando por processo de urbanização acelerado e mal planejado, o que pode comprometer sua qualidade ambiental e, por consequência, sua qualidade de vida.

Estudos mostram que regiões urbanizadas são núcleos de calor localizados em volta de áreas rurais com temperaturas menores e, por isso, denominam-se Ilhas de Calor Urbanas (ICU) (Oke, 1987; Voogt e Oke, 2003). Apesar de autores como Alves et al. (2010) acreditarem que uma ICU pode também se originar independentemente da ação humana, como por conta da ação de ventos regionais. Existem vários estudos que indicam que os efeitos da urbanização contribuem fortemente para sua formação: a escassez de áreas verdes e de superfícies líquidas, essenciais para balancear os níveis de umidade e temperatura, resulta em menor evaporação, diminuindo o fluxo de calor latente e aumentando o fluxo de calor sensível (Gamarra et al., 2014); maior emissão de calor devido à grande quantidade de indústrias e veículos, que, além disso, emitem poluentes atmosféricos com potencial para influenciar na qualidade do ar local (Alves et al., 2010); os materiais das construções civis, muito frequentes nas áreas urbanas, absorvem radiação de ondas curtas, conservam calor durante o dia e o liberam à noite, tanto devido às suas propriedades térmicas quanto ao efeito do albedo (Oke,1982; Gamarra et al., 2014). Além disso, a maior quantidade de poluentes atmosféricos reflete no aumento da entrada de ondas longas e a presença de prédios altos diminui o fator de visão do céu ("sky view"), reduzindo as perdas de radiação de ondas longas nas ruas e cânions urbanos (Oke, 1987; Oke et al., 1991).

As populações que residem nestes ambientes já podem sentir os efeitos do aumento da temperatura média e uma alteração nos padrões de precipitação. A Região Metropolitana de São Paulo (RMSP), por exemplo, tem sofrido rotineiramente com os eventos severos nas últimas décadas, por conta de extremos pluviométricos, como pe- ríodos de estiagem, enchentes e/ou destruição de estruturas urbanas. Há estudos que indicam indícios de mudanças nos padrões de precipitação da RMSP (Xavier et al., 1994), principalmente nas décadas de 1980 e 1990 e no ano 2000 até a atualidade (Sant'Anna Neto, 1999; Raimundo et al., 2010). As mudanças observadas nas décadas de 1980 e 1990 podem estar associadas ao modo de variabilidade climática El Niño-Oscilação Sul (ENOS), que foram mais fortes e frequentes neste período (Arndt et al., 2010), porém, a partir de 2000, o aumento significativo da urbanização da RMSP pode estar relacionado com essa mudança de padrão. Esta dicotomia abre espaço para questionamentos, tais como: a urbanização de uma região pode influenciar as condições atmosféricas a ponto de modificar o regime de chuva? Se sim, em que magnitude?

Freitas e Dias (2005) constataram, por meio de modelagem numérica, que há grandes diferenças de temperatura entre o espaço urbano da RMSP e áreas circunvizinhas, o que contribui para formação de zonas de convergência e divergência nestas áreas e em áreas remotas que, por sua vez, modifica a altura da Camada Limite Planetária (CLP) na região e intervém na velocidade do vento em níveis mais baixos. Grossman-Clarke et al. (2005) utilizaram o NCAR/Mesoscale Model v. 5 - MM5 com diferentes cenários de usos do solo para estudar os efeitos das modificações urbanas nas variáveis de meteorológicas na Região Metropolitana de Phoenix (Arizona, Estados Unidos), do dia 7 de junho de 1998 a 10 de junho de 1998, e concluíram principalmente que tal mudança resultou no aumento da velocidade do vento durante o dia, na amenização das temperaturas diurnas e noturnas e também influenciou a altura da CLP.

Ezber et al. (2007) também investigaram os impactos da urbanização nas variáveis meteorológicas por meio de ferramentas estatísticas e do modelo MM5, na cidade de Istambul, Turquia, durante o período de 1951 a 2004, e igualmente concluíram que a urbanização contribui significativamente com o aquecimento da atmosfera local e exerce grande influência na velocidade do vento, que reduziu ao longo dos anos com o aumento da área urbanizada. Zhang et al. (2007) analisaram os dados de precipitação de 1980 a 2003 na Região Metropolitana de Pequim (China), percebendo que houve uma diminuição da quantidade de eventos de chuva, principalmente nos locais onde se encontram seus principais reservatórios, fato que se correlaciona estatisticamente com a expansão e desenvolvimento urbano da região, o que motivou os autores a estudarem a influência da urbanização nos eventos de precipitação em Pequim nesse período. Foi utilizado o MM5 para a realização de simulações de um evento de chuva de verão com diferentes 
cenários de tipo e uso do solo, e concluíram que a urbanização reduz a produção de evaporação, aumenta as temperaturas de superfície e o fluxo de calor sensível.

Miao et al. (2009) investigaram a influência da urbanização nos fortes eventos de chuva ocorridos, também na cidade de Beijing (China), por meio de simulações numéricas com o Weather Research and Forecasting Model WRF, sucessor do MM5, utilizando diferentes cenários de tipo e uso do solo. Realizaram simulações para um horizonte de 24 horas para o dia 1 de agosto de 2006, e concluíram que a urbanização exerceu forte influência no comportamento da tempestade, além de constatarem a partir de imagens de radar e dados observados que, no geral, o WRF realizou bem as simulações.

Yu e Liu (2015) estudaram os efeitos da urbanização em um evento de precipitação ocorrido em julho de 2012, também em Beijing, utilizando o WRF com diferentes cenários de tipo e uso do solo, concluindo que, de fato, a urbanização influenciou, neste estudo de caso, a distribuição e a intensidade da precipitação. Lin et al. (2016) estudaram os impactos da urbanização na temperatura do ar na superfície entre os anos de 1980 e 2009 nas regiões urbanas chinesas de Beijing-Tianjin-Hebei, delta do rio Yangtze e Pérola Delta do rio, por meio do modelo CLM4.5, considerando um cenário urbano e outro não urbano, e concluíram que a urbanização contribuiu com cerca de $9,70 \%, 10,3 \%$ e $9,68 \%$ para o aumento da temperatura média diária ao longo dos 30 anos, nas respectivas regiões, acreditando que esses resultados tenham sido subestimados, mesmo não sendo grande a amplitude desta subestimativa. Shastri et al. (2014) estudaram os efeitos da urbanização nos eventos extremos de precipitação em Mumbai (Índia) com métodos estatísticos e com o uso do modelo WRF, e concluíram que a urbanização tem influência significativa nos padrões regionais de precipitação e nos eventos extremos. Estes resultados incentivam outros estudos a esse respeito com a utilização de modelos numéricos.

Diante do exposto, este trabalho visa contextualizar a evolução dos padrões de precipitação da RMSP numericamente, e a possível influência da urbanização, a partir da utilização do WRF, com diferentes cenários de urbanização, provenientes de alterações em suas configurações de tipo e uso do solo e estatística descritiva.

\section{Metodologia}

\subsection{Avaliações estatísticas da série histórica de precipitação na RMSP}

Os eventos de precipitação oriundos de processos convectivos são frequentes entre a primavera e o verão austral, por conta da maior absorção de radiação e emissão de calor da superfície, caracterizando, portanto, o período úmido da RMSP e da região sudeste (Reboita et al., 2010). Dados pluviométricos mensais (novembro a março) foram selecionados no período de 1933 a 2014, provenientes da estação do Instituto de Astronomia, Geofísica e Ciências Atmosféricas da Universidade de São Paulo (IAG-USP), na latitude 2339'4.10" S e longitude 46³7'20.74” O, a $799 \mathrm{~m}$ acima do nível médio do mar (USP, 2015). Originalmente, em 1933, a estação foi instalada em região rural, entretanto, atualmente encontra-se cercada por região urbanizada, com pelo menos $1 \mathrm{~km}$ de distância entre a estação e as ruas e avenidas (Dias et al., 2013).

Para a análise da série temporal, foram elaboradas figuras contendo: a evolução da média mensal da precipitação, os números de dias chuvosos de cada mês, o número de dias com chuva maior ou igual do que a precipitação média somada a dois, três e quatro desvios padrão. Dezembro foi o mês que apresentou resultados que mais caracterizam uma modificação no comportamento dos eventos de precipitação da região ao longo dos anos, por isso, nesse trabalho serão mostradas somente as análises referentes a esse mês.

\subsection{Simulações com o WRF}

A avaliação da influência da urbanização na circulação local se deu por meio de simulações numéricas, elaboradas com o modelo de mesoescala WRF, versão 3.5. Maiores detalhes sobre o WRF são encontrados em Skamarock et al. (2008). O modelo foi configurado com três grades aninhadas utilizando interação unidirecional (one way), em que os fluxos entre as grades ocorrem apenas das grades de menor resolução para as de maior resolução. As resoluções espaciais horizontais são 27 km, 9 km e 3 km, conforme a Fig. 1, e 30 níveis verticais. Todas as grades utilizam passo de tempo de $60 \mathrm{~s}$ e topografia de resolução espacial de aproximadamente $900 \mathrm{~m}$. São apresentados apenas os resultados do domínio de maior resolução $(3 \mathrm{~km})$,

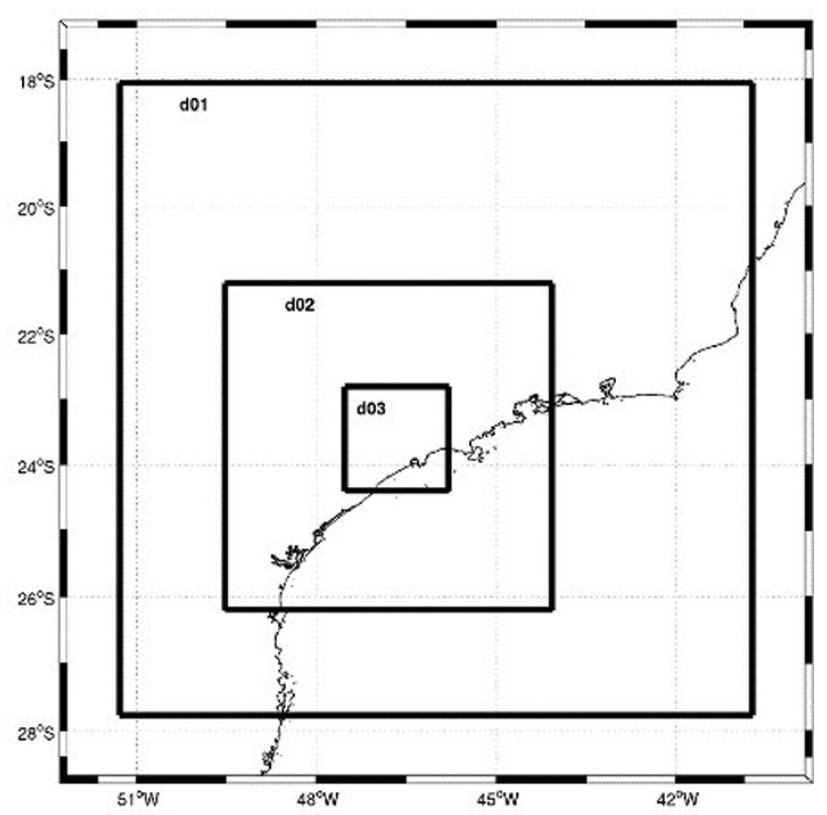

Figura 1 - Domínios com 27 km, 9 km e 3 km de resolução. 
que contém $61 \times 61$ pontos centralizados na capital São Paulo, abrangendo toda a RMSP e parte das Regiões Metropolitanas de Campinas, da Baixada Santista e das Regiões Administrativas de Sorocaba e de São José dos Campos, entre as latitudes $47^{\circ} 36^{\prime} 00^{\prime}$ ' $\mathrm{O}$ e $45^{\circ} 48^{\prime} 00^{\prime}$ ' $\mathrm{O}$ e longitudes $24^{\circ} 24^{\prime} 00^{\prime \prime} \mathrm{S}$ e $22^{\circ} 48^{\prime} 00^{\prime \prime} \mathrm{S}$.

Como condições iniciais e de contorno, foram utilizados os resultados do Global Forecast System (GFS), com resolução espacial horizontal de $0.5^{\circ}$ e previsões a cada $3 \mathrm{~h}$. As parametrizações físicas utilizadas nestas simulações são mostradas na Tabela 1 .

As simulações foram feitas a partir de três cenários distintos de urbanização na RMSP, ilustrados nas Figs. 2a, $2 b$ e $2 c$, sendo referentes a: 1-mancha urbana padrão do modelo (ou simplesmente "padrão"), correspondente ao tipo e uso do solo da região de estudo disponibilizado com o modelo WRF, a partir da base de dados da United States Geological Survey (USGS); 2-mancha urbana ampliada, a partir da tendência de expansão urbana dos últimos anos; 3-mancha urbana substituída por floresta nativa (ou apenas "floresta").

Para a construção dos cenários 2 e 3 , os arquivos de tipo e uso do solo originais (cenário 1) do modelo foram alterados com a utilização do software MATLAB ${ }^{\circledR}$ versão
R2012B. O tipo e uso do solo escolhido para substituir a mancha urbana no cenário "floresta" foi o "evergreen broadleaf" (código 13), por ser o tipo de vegetação do tipo floresta predominante no entorno da área urbanizada, de acordo com a classificação do WRF. Essas modificações foram feitas diretamente no arquivo wrf input e não nos arquivos netcdf gerados pelo geogrid (geo_em.d $<$ número_da_grade $>$ ), como indicado no manual do WRF, pois, quando testados desta forma, não geraram alteração nos resultados.

Os dados da estação pluviométrica do IAG foram utilizados para as análises estatísticas e também para o entendimento do comportamento histórico da série de precipitação na região e para a escolha das datas das simulações no WRF, que deveriam ser aquelas com eventos de precipitação significativos em termos de total precipitado e, principalmente, de origem convectiva. Como a precipitação pode ser oriunda da combinação de diversos sistemas que atuam na região, e que não necessariamente estão diretamente relacionados com a urbanização, como a Zona de Convergência do Atlântico Sul (ZCAS) (Rocha e Gandu, 1996; Vieira et al., 2014), linhas de instabilidade (Scolar e Dias, 1982; Oliveira et al., 2015), sistemas frontais (Satyamurty et al., 1990) e circulação de brisas marítimas
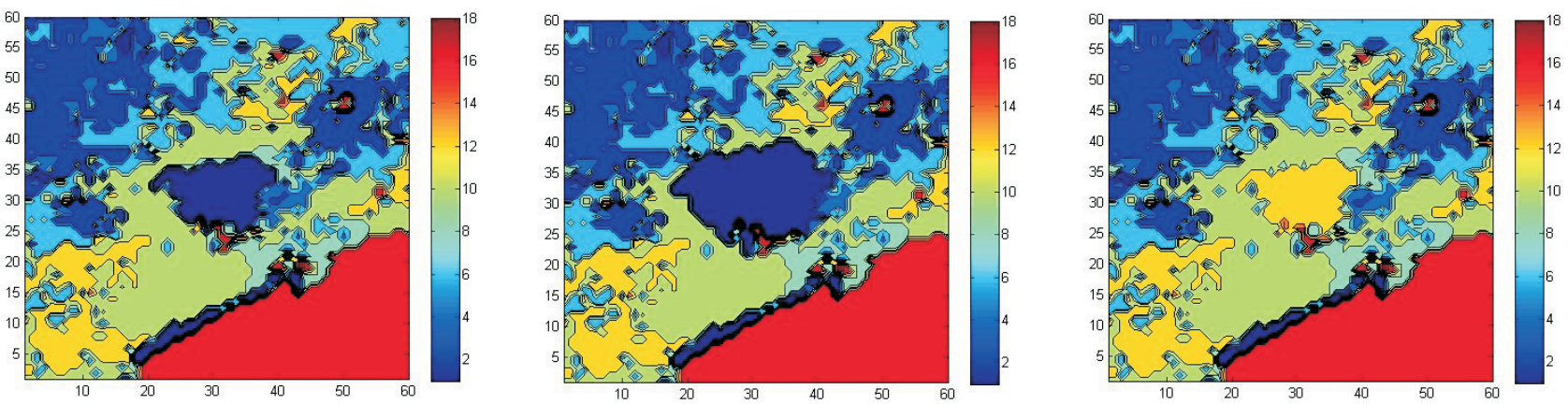

Figura 2 - Tipo de uso do solo utilizados no modelo WRF. (a) tipo e uso do solo padrão do modelo - cenário 1 (USGS, 2013); (b) Tipo de uso do solo com a urbanização ampliada - cenário 2 e (c) Tipo de uso do solo para com a área urbana substituída por floresta nativa - cenário 3. Os números representam as categorias de tipo e uso do solo da USGS: 1. Urban and Built-up Land; 2. Dryland Cropland and Pasture; 3. Irrigated Cropland and Pasture; 4. Mixed Dryland/Irrigated Cropland and Pasture; 5. Cropland/Grassland Mosaic; 6. Cropland/Woodland Mosaic; 7. Grassland; 8. Shrubland/Grassland; 9. Savanna; 10. Deciduous Broadleaf Forest; 11. Deciduous Needleleaf Forest; 12. Evergreen Broadleaf; 13. Evergreen Needleleaf; 14. Mixed Forest; 15. Water Bodies; 16. Herbaceous Wetland; 17. Wooden Wetland; 18. Wooden Wetland; 19. Barren or Sparsely Vegetated; 20. Herbaceous Tundra; 21. Wooded Tundra; 22. Mixed Tundra; 23. Bare Ground; 24. Snow or Ice.

Tabela 1 - Parametrizações utilizadas nos experimentos.

\begin{tabular}{lll}
\hline Esquemas físicos & Parametrizações & Referências \\
\hline Cúmulos e convecção & Kain-Fritsch scheme & Kain, 2004 \\
Microfísica de nuvens & WRF Single Moment 3 & Hong, Dudhia and Chen, 2004 \\
Radiação de onda curta & Dudhia scheme & Dudhia, 1989 \\
Radiação de onda longa & Rapid Radiative Transfer Model & Mlawer et al., 1997 \\
Camada limite planetária & Yonsei University Scheme & Hong et al., 2006 \\
Camada de superfície & MM5 similarity scheme & Paulson 1970; Dyer and Hicks 1970; Webb 1970; Zhang and Anthes 1982 \\
Modelo de solo & Unified Noah Land Surface Model & Tewari et al., 2004 \\
\hline
\end{tabular}


(Reboita et al., 2010), foi feita uma triagem com o auxílio de imagens de satélite realçadas, do canal infravermelho do METEOSAT - canal 9 (INPE, 2015). Além disso, foram utilizadas imagens de radar Banda S localizado em São Roque do Departamento de Controle do Espaço Aéreo (DECEA) (Angelis et al., 2006), visando a escolha de três datas cujos eventos de precipitação fossem oriundos, primordialmente, de processos convectivos de microescala, já que estes poderiam ser alterados pela influência das ICU.

As datas selecionadas foram 24/01/2014, 26/11/2014 e 22/12/2014. Nesta última, a atmosfera na RMSP sofreu a influência de uma frente fria, de modo que foram analisados os resultados da modelagem somente no período préfrontal. Foram feitas quatro simulações para cada uma delas, com o objetivo de comparar os resultados e identificar onde e como a presença da região urbanizada, e o seu tamanho, modifica o comportamento das variáveis atmosféricas, a saber: uma com o cenário 1 (padrão), outra para o 3 (floresta) e duas para o 2 (urbanização ampliada), sendo uma com as parametrizações "cumulus" e "meio urbano" (opção $s f \_u r b a n \_p h y s i c s$ ) ligadas e a outra não, para se testar a sensibilidade do modelo também a estas parametrizações.

Os resultados da modelagem serão apresentados na forma de figuras com o mesmo pano de fundo: a região urbanizada da RMSP do ano de 2005, disponibilizada em formato shapefile pelo Instituto Brasileiro de Geografia e
Estatística (IBGE, 2015). Mesmo nas figuras referentes aos cenários "floresta" ou "urbanização ampliada", manteve-se a região urbana de 2005 em todas para possibilitar a comparação entre elas. As variáveis meteorológicas analisadas em cada uma das datas foram o calor sensível, a temperatura a dois metros do solo e a precipitação acumulada em três horas. Em seguida, é feita uma discussão sobre as características físicas dos processos de convecção associados com a mancha urbana com exemplos do comportamento dessas variáveis e também do ômega a $850 \mathrm{hPa}$ e da diferença relativa da umidade específica a $1.000 \mathrm{hPa}$. Vale ressaltar que, a priori, serão desconsiderados os efeitos complexos da topografia e da relação terra-mar nos padrões atmosféricos da região de estudo, ou seja, o foco da discussão estará na diferença observada em os campos de circulação e convecção, oriundos somente das alterações na cobertura do solo, já que estes foram os únicos parâmetros alterados nestas simulações.

\section{Resultados e Discussão}

\subsection{Resultados das avaliações estatísticas da série histórica de precipitação na RMSP}

No mês de dezembro verifica-se uma diminuição do número de dias chuvosos, principalmente nos últimos 10 anos (Fig. 3). Também se observa um aumento significa-

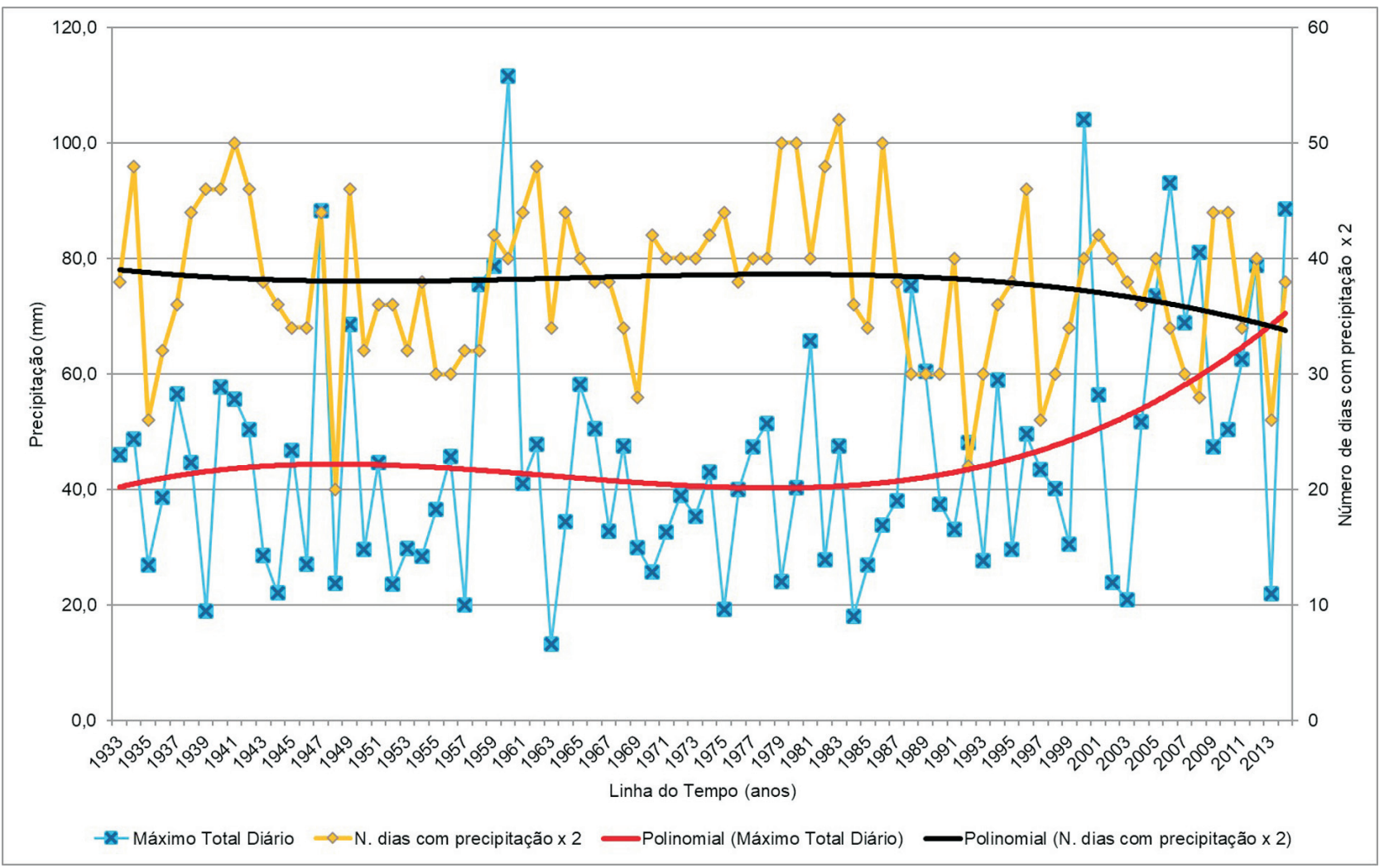

Figura 3 - Precipitação máxima total diária (linha azul) e número de dias com precipitação acima de 0,2 mm (linha amarela) no mês de dezembro na estação do IAG-USP e suas respectivas linhas de tendência. 
tivo da intensidade da chuva máxima diária em dezembro, principalmente nos últimos 20 anos.

$\mathrm{Na}$ análise dos números de dias com precipitação igual ou superior à média mensal de dezembro $(6 \mathrm{~mm})$, mais dois, três e quatro desvios-padrão, que resultam em, respectivamente, $29 \mathrm{~mm}, 41 \mathrm{~mm}$ e $53 \mathrm{~mm}$, percebe-se que a quantidade de dias com essas características tem aumentado a partir da década de 1990, o que é um indício de que se tem observado mais dias com eventos de chuvas intensas, sem necessariamente se observar um aumento no volume total de precipitação. Os resultados representados pela Fig. 4 comprovam tal comportamento no mês de dezembro.

\subsection{Resultados das simulações numéricas com o WRF}

\subsubsection{Dia 24 de janeiro de 2014}

O primeiro período de simulações compreendeu da 0000 UTC do dia 24 a 0000 UTC do dia 26 de janeiro de 2014. Na Fig. 5, uma mancha azul em cima da área urbanizada e arredores, a qual representa a chuva acumulada com intensidades entre $2 \mathrm{~mm}$ e $20 \mathrm{~mm}$. Um núcleo de
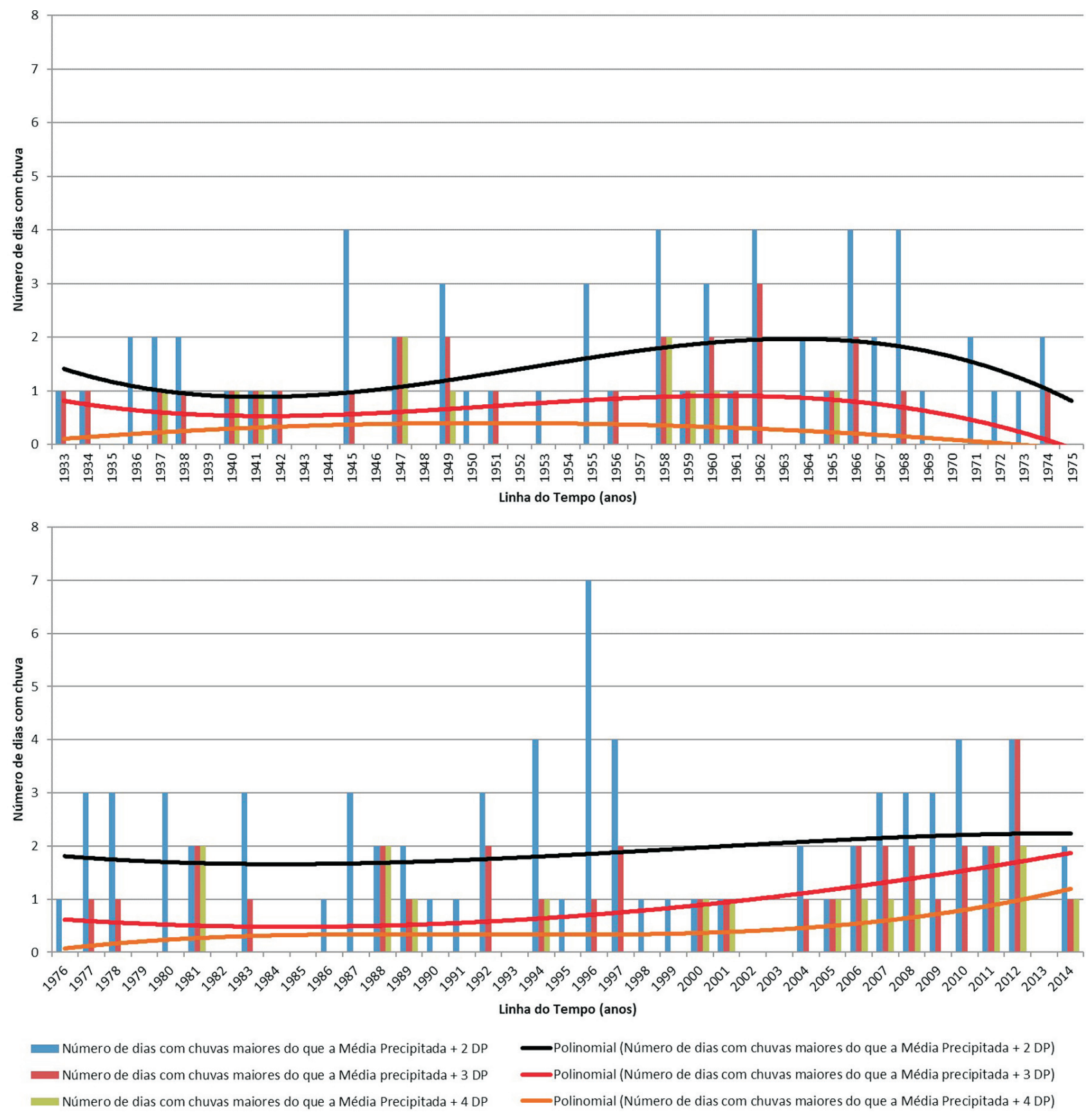

Figura 4 - Número de dias no mês de dezembro na estação do IAG-USP com precipitação maior do que a média mensal mais duas (linha azul), três (linha vermelha) e quatro (linha verde) vezes o seu desvio padrão. 

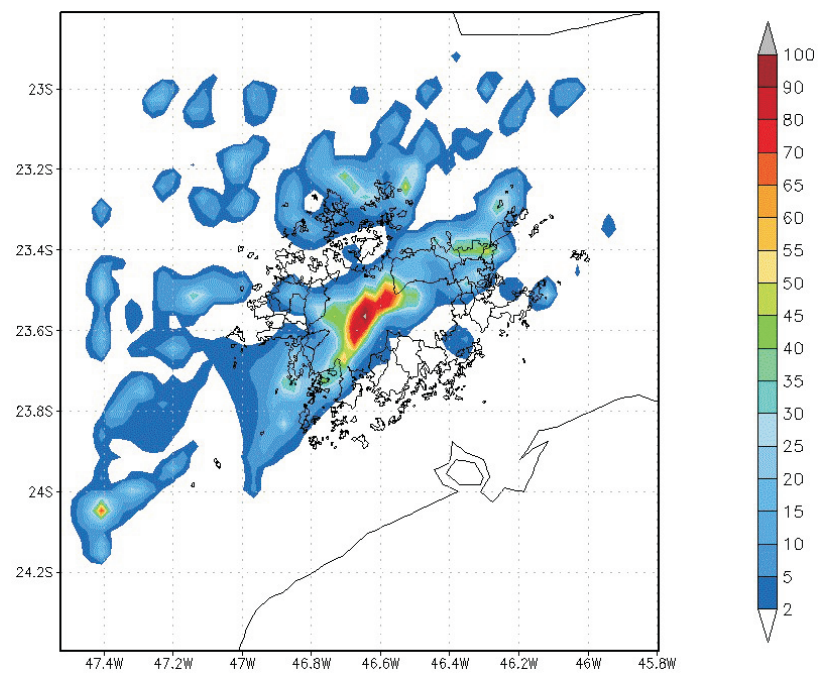

Figura 5 - Precipitação de acumulada das 1800 UTC às 2100 UTC em 25/01/2014 no cenário padrão em $\mathrm{mm}$.

intensidade variou de 45 a $100 \mathrm{~mm}$ do centro para as bordas no interior da mancha urbana e quatro pequenos núcleos de $35 \mathrm{~mm}$ a $45 \mathrm{~mm}$ no seu entorno. Três horas antes (às 1800 UTC), o calor sensível ascendente era mais intenso em diversos pontos no interior da mancha urbana em relação ao entorno, atingindo valores maiores do que $300 \mathrm{Wm}^{-2}$ (Fig. 6). Neste horário, a temperatura também era mais alta no centro da mancha urbana (entre $28^{\circ} \mathrm{C}$ e $33^{\circ} \mathrm{C}$ ) do que em sua borda (entre $20^{\circ} \mathrm{C}$ e $28^{\circ} \mathrm{C}$ ) (Fig. 7).

Os resultados da segunda simulação para este período, com a alteração do tipo e uso do solo de padrão para floresta, mostraram, no mesmo intervalo, um núcleo de precipitação acumulada no interior da região urbana e quatro núcleos menores no seu entorno com intensidades variando entre $40 \mathrm{~mm}$ e $65 \mathrm{~mm}$ e também uma mancha de precipitação acumulada entre $2 \mathrm{~mm}$ e $20 \mathrm{~mm}$ (Fig. 8). Nas
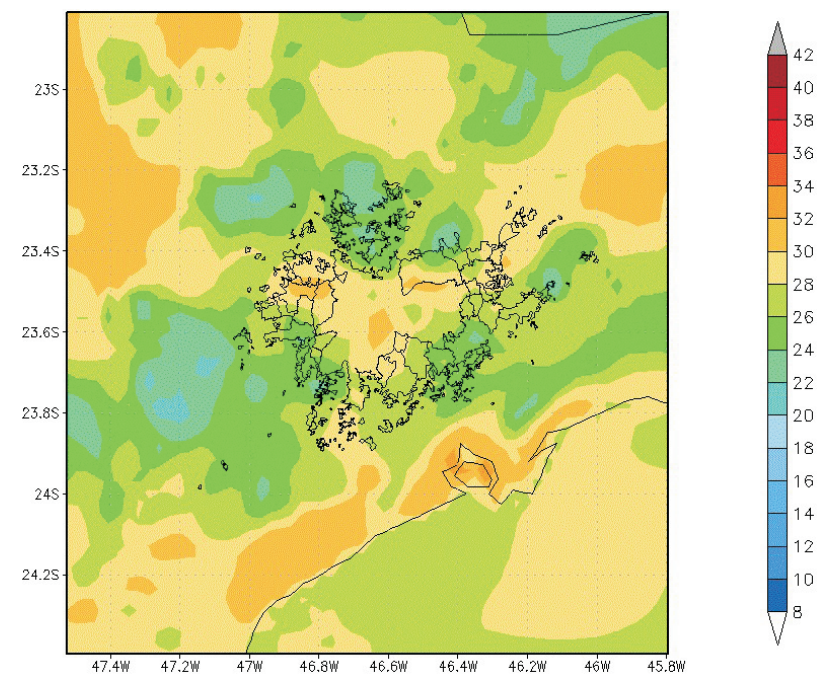

Figura 7 - Temperatura a dois metros do solo às 1800 UTC de 25/01/2014 no cenário padrão em ${ }^{\circ} \mathrm{C}$.

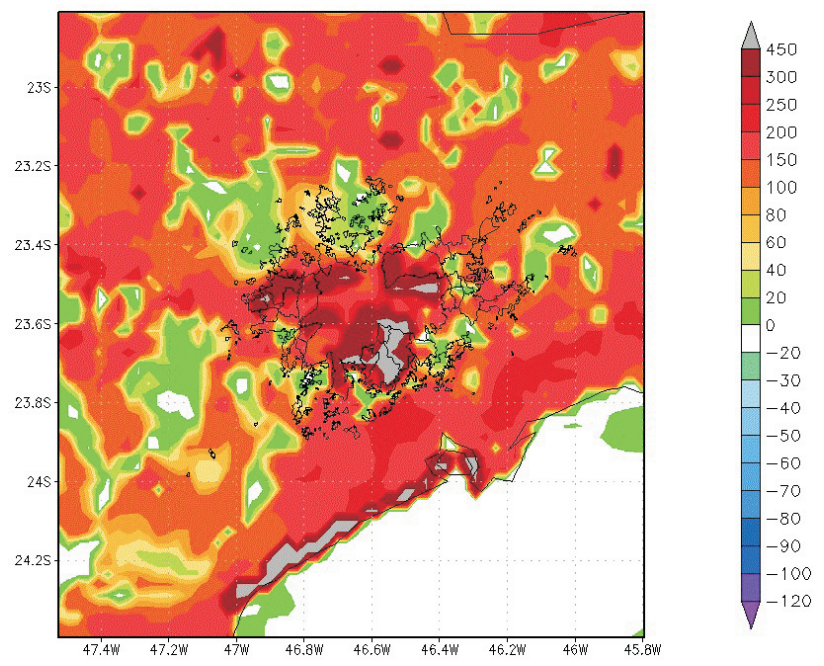

Figura 6 - Calor sensível às 1800 UTC de 25/01/2014 no cenário padrão $\mathrm{em} \mathrm{W} / \mathrm{m}^{2}$.

três horas anteriores (às 1800 UTC), o calor sensível mostrou uma distribuição uniforme ao longo do domínio, com variação entre $150 \mathrm{Wm}^{-2}$ e $250 \mathrm{Wm}^{-2}$, com alguns pontos entre 0 e $40 \mathrm{Wm}^{-2}$ e poucos entre $250 \mathrm{Wm}^{-2}$ e $450 \mathrm{Wm}^{-2}$ (Fig. 9). Em relação à temperatura, não se percebe relação entre a localização das regiões com temperaturas mais altas ou mais baixas e o tipo de solo, ao contrário do que ocorreu no cenário padrão (Fig. 10). Desta forma, percebe-se que a precipitação se mostrou espalhada e menos concentrada e com a alteração do tipo e uso do solo, o que permite inferir que a presença da urbanização, neste caso, exerceu um papel importante na concentração da precipitação, principalmente dentro e nas bordas da área que a limita.

Com a alteração do tipo e uso do solo para urbanização ampliada, percebeu-se que o aumento da área urbanizada fez com que surgissem no seu interior apenas dois

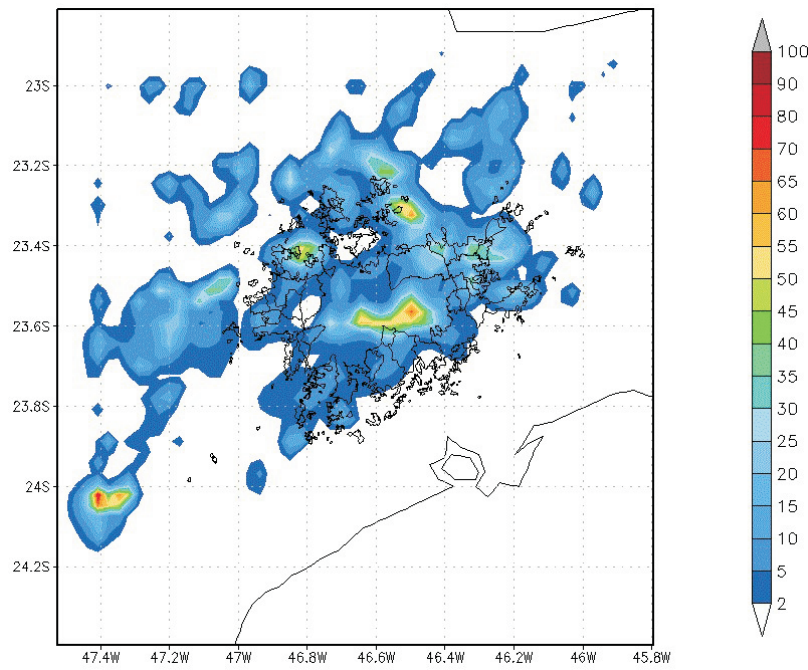

Figura 8 - Precipitação de acumulada das 1800 UTC às 2100 UTC em 25/01/2014 no cenário floresta em $\mathrm{mm}$. 

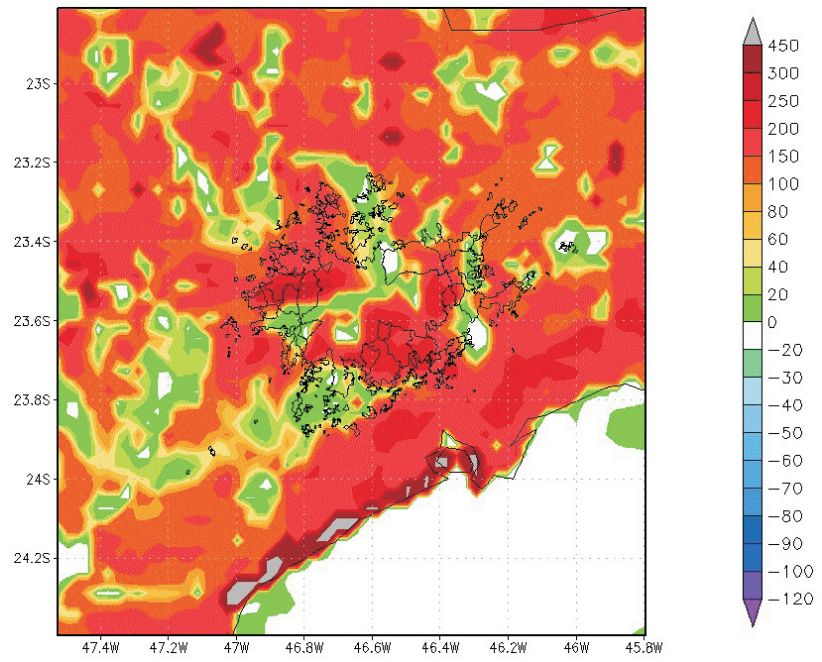

Figura 9 - Calor sensível às 1800 UTC de 25/01/2014 no cenário floresta $\mathrm{em} \mathrm{W} / \mathrm{m}^{2}$.
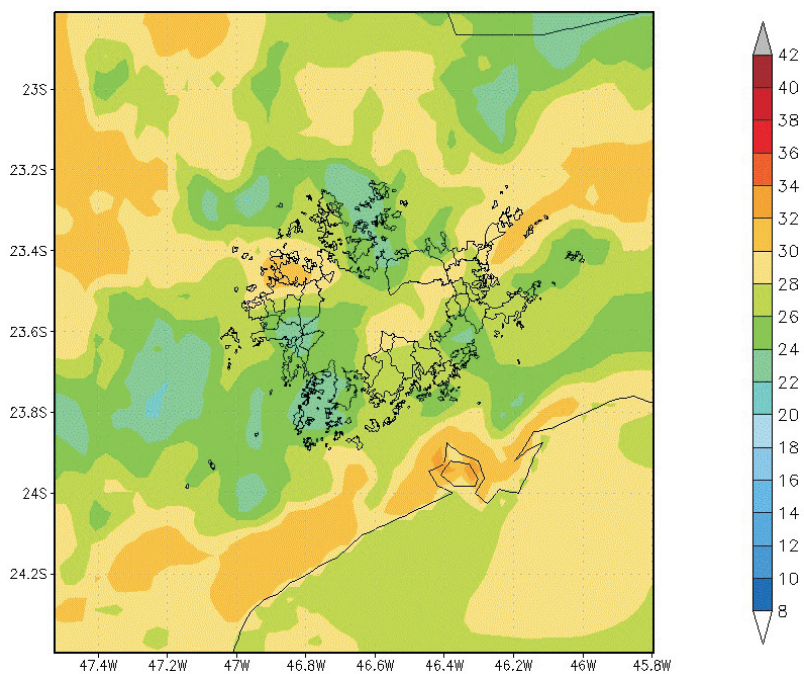

Figura 10 - Temperatura a dois metros do solo às 1800 UTC de 25/01/2014 no cenário floresta em ${ }^{\circ} \mathrm{C}$.

pequenos núcleos de precipitação com intensidade entre $30 \mathrm{~mm}$ e $45 \mathrm{~mm}$, enquanto dois outros núcleos, entre $40 \mathrm{~mm}$ e $90 \mathrm{~mm}$, apareceram nas bordas da região, todos inseridos na mancha urbana (Fig. 11). Ainda nas bordas, há vários pequenos núcleos com intensidades entre $35 \mathrm{~mm}$ e $50 \mathrm{~mm}$. O calor sensível e a temperatura nas três horas anteriores se comportaram de forma parecida com o primeiro cenário (padrão), apresentando maior intensidade na área onde cresceu a mancha urbana, conforme ilustrado nas Figs. 12 e 13. Desta forma, infere-se que o aumento da área urbanizada tendeu a concentrar ainda mais a precipitação nas bordas da área urbanizada.

\subsubsection{Dia 26 de novembro de 2014}

O segundo período de simulações compreendeu da 0000 UTC do dia 26 a 0000 UTC do dia 28 de novembro de 2014. O resultado obtido, considerando o tipo e uso do solo
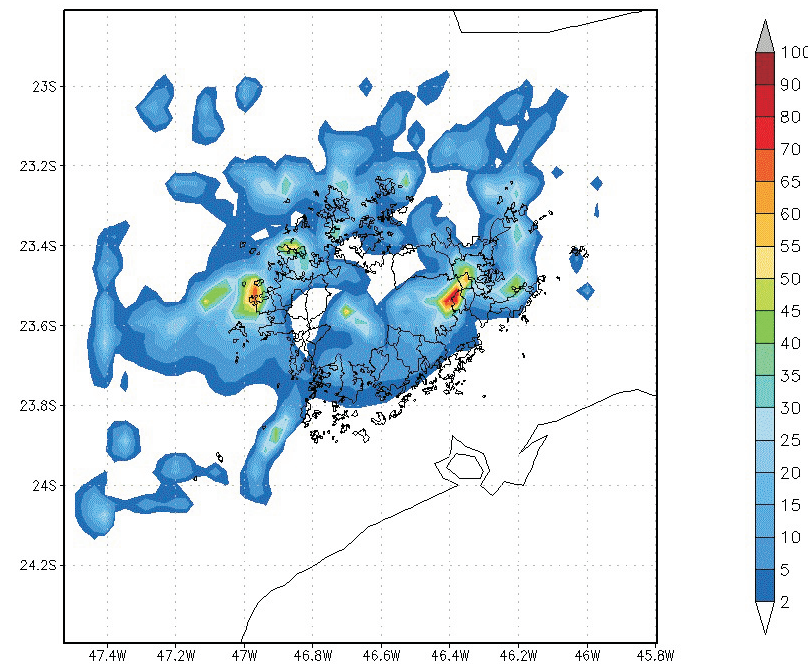

Figura 11 - Precipitação de acumulada das 1800 UTC às 2100 UTC em 25/01/2014 no cenário urbanização ampliada em mm.
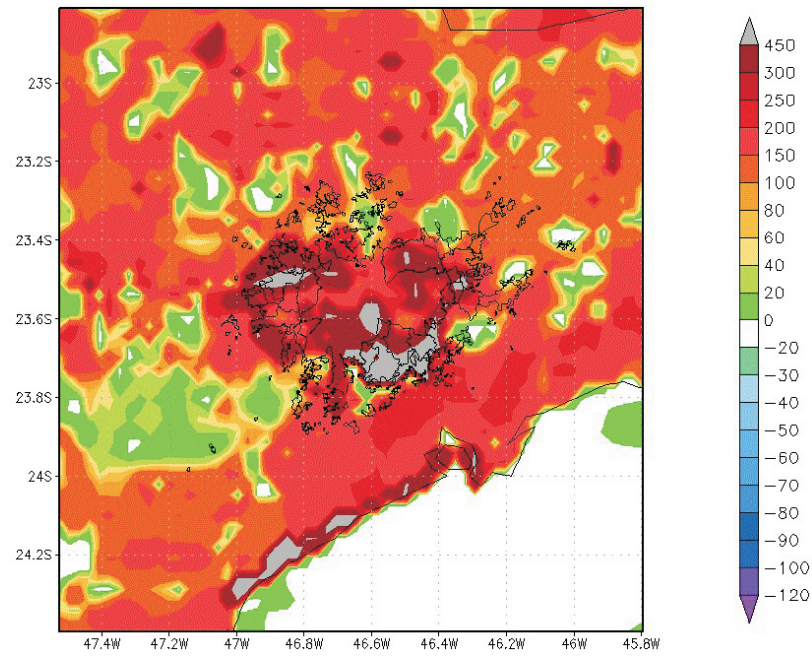

Figura 12 - Calor sensível às 1800 UTC de 25/01/2014 no cenário urbanização ampliada em $\mathrm{W} / \mathrm{m}^{2}$.
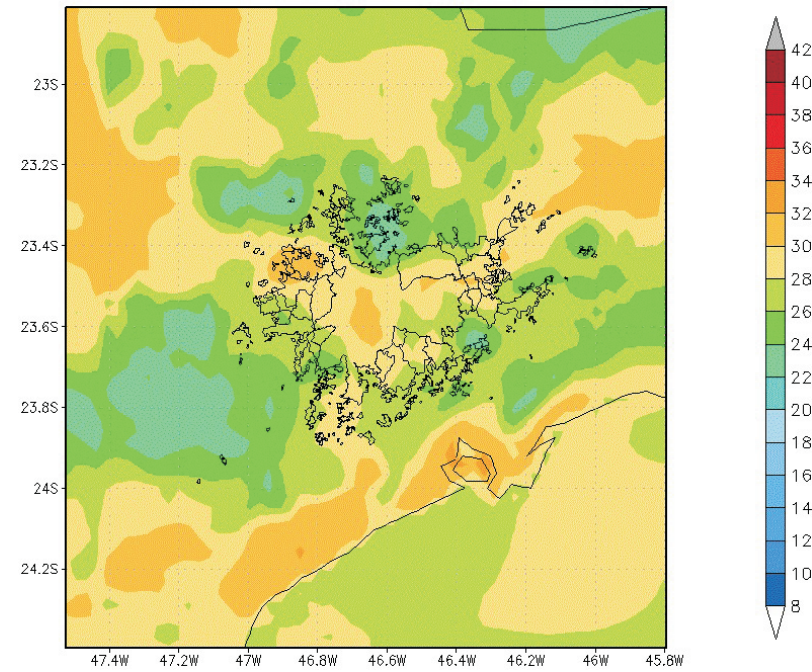

Figura 13 - Temperatura a dois metros do solo às 1800 UTC de 25/01/2014 no cenário urbanização ampliada $\mathrm{em}{ }^{\circ} \mathrm{C}$. 
padrão, no dia 26 (Fig. 14), mostrou a precipitação acumulada de 1800 às 2100 UTC, variando entre $2 \mathrm{~mm}$ e $30 \mathrm{~mm}$ e um pequeno núcleo de $45 \mathrm{~mm}$ a $80 \mathrm{~mm}$ em parte da mancha urbana, enquanto núcleos maiores de $45 \mathrm{~mm}$ a $90 \mathrm{~mm}$ apareceram fora desta região. Não houve diferença significativa dos resultados da simulação da precipitação acumulada deste cenário para o 3 (floresta), conforme a Fig. 15, mas no cenário 2 (maior urbanização), em que as parametrizações "cumulus" e "urbanização" foram ativadas, alguns núcleos de precipitação presentes no cenário 1 aumentaram significativamente (Fig. 16). Em relação ao calor sensível, nas três horas anteriores (às 1800 UTC), o cenário 2 apresentou uma mancha maior e mais forte no centro do domínio (Fig. 17) do que no cenário 1 (Fig. 18), isso mostra que a intensidade do calor sensível ascendente acompanhou o aumento da região urbanizada. Quase não houve diferença de intensidade do calor sensível ao longo do domínio no cenário 3 , apresentando menor intensidade e padrão
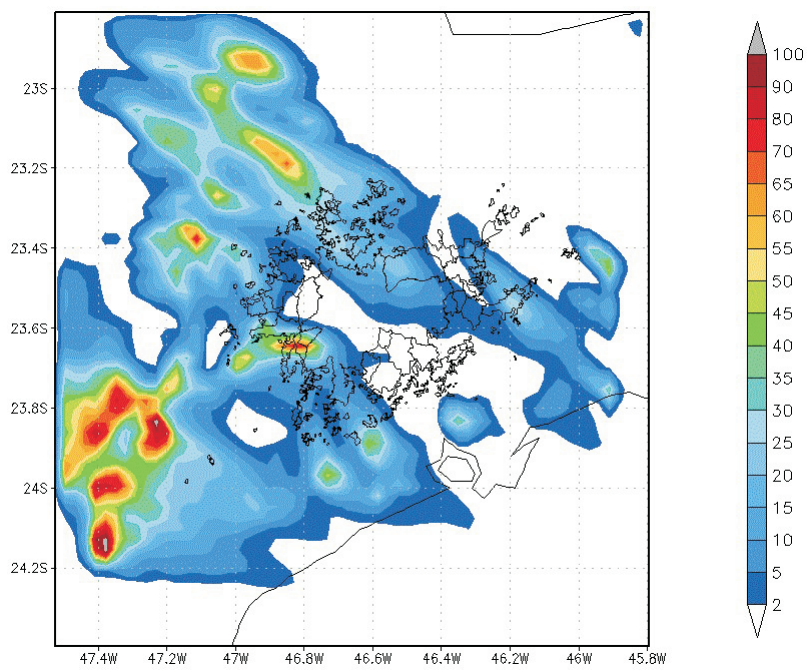

Figura 14 - Precipitação de acumulada das 1800 UTC às 2100 UTC em 26/11/2014 no cenário padrão $\mathrm{em} \mathrm{mm}$.
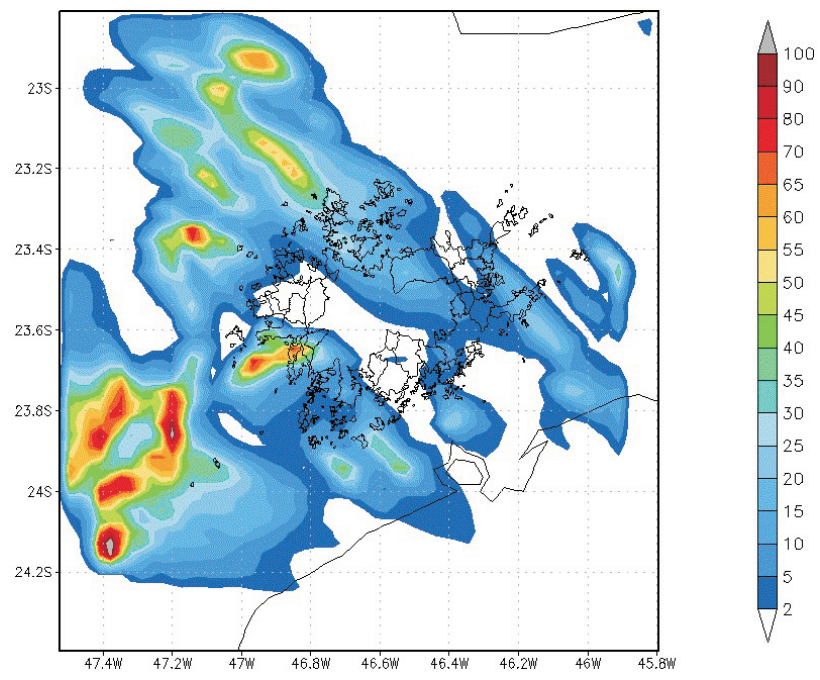

Figura 15 - Precipitação de acumulada das 1800 UTC às 2100 UTC em 26/11/2014 no cenário floresta em $\mathrm{mm}$.

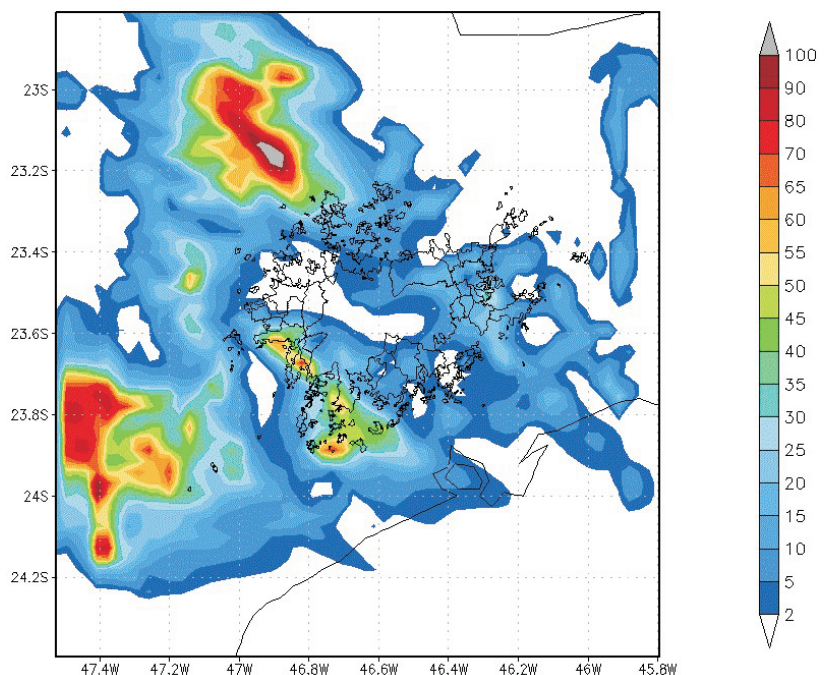

Figura 16 - Precipitação de acumulada das 1800 UTC às 2100 UTC em 26/11/2014 no cenário urbanização em mm ampliada com parametrizações "cumulus" e "urbana" ativadas.
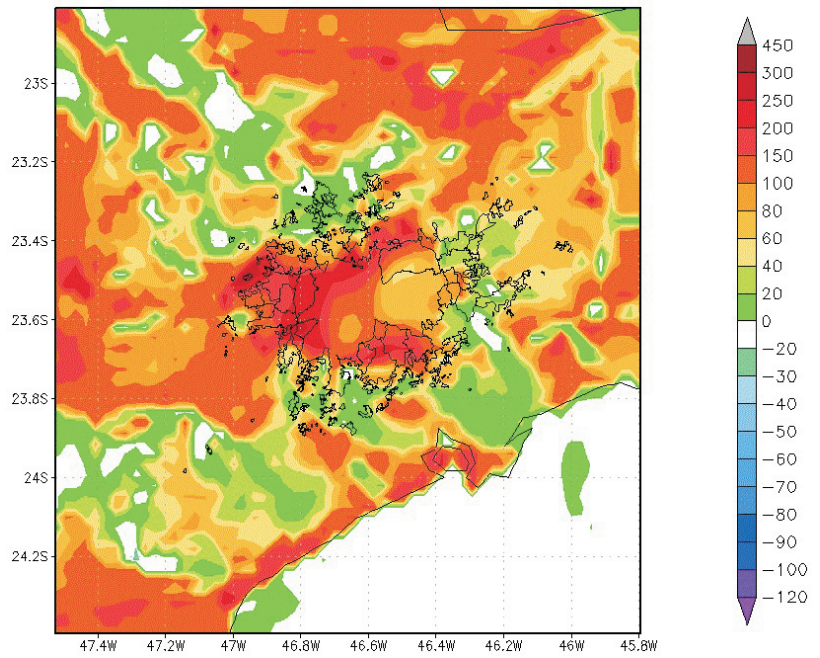

Figura 17 - Calor sensível às 1800 UTC de 26/11/2014 no cenário urbanização ampliada em W/m² com parametrizações "cumulus" e "urbana" ativadas.
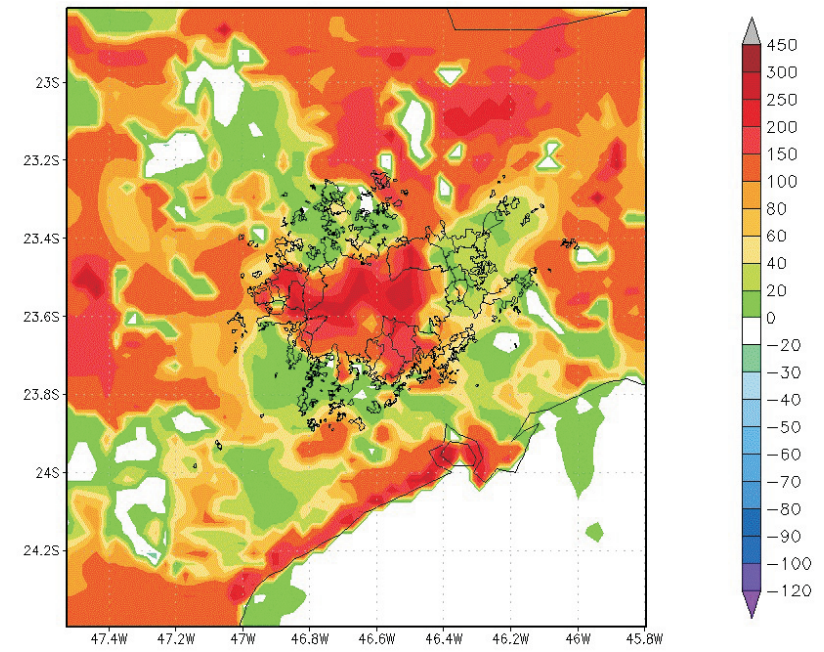

Figura 18 - Calor sensível às 1800 UTC de 26/11/2014 no cenário padrão $\mathrm{em} \mathrm{W} / \mathrm{m}^{2}$. 
mais homogêneo do que o simulado nos outros cenários (Fig. 19). A temperatura nos cenários 1 e 2 apresentou distribuições similares na região central do domínio (Figs. 20 e 21). Em contrapartida, no cenário 3, os mesmos intervalos de temperatura abrangem uma área menor em comparação aos cenários anteriores (Fig. 22).

\subsubsection{Dia 22 de dezembro de 2014}

O terceiro período de simulações compreendeu da 0000 UTC do dia 22 a 0000 UTC do dia 24 de dezembro de 2014. Neste período, devido à aproximação de uma frente fria, as simulações compreenderam uma situação de préfrontal na RMSP, com um padrão diferente das situações anteriores, que tiveram a convecção livre associada com o aquecimento da superfície como a principal responsável
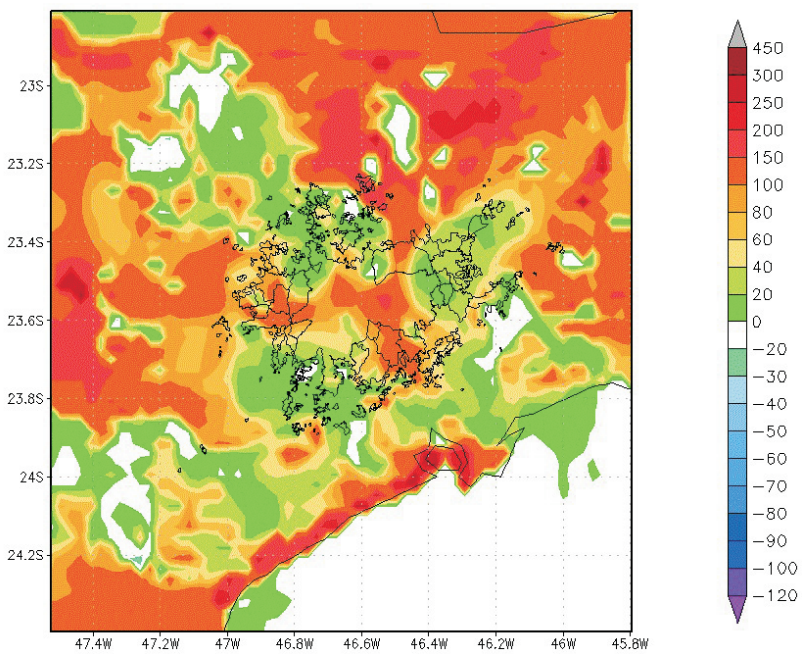

Figura 19 - Calor sensível às 1800 UTC de 26/11/2014 no cenário floresta $\mathrm{em} \mathrm{W} / \mathrm{m}^{2}$.
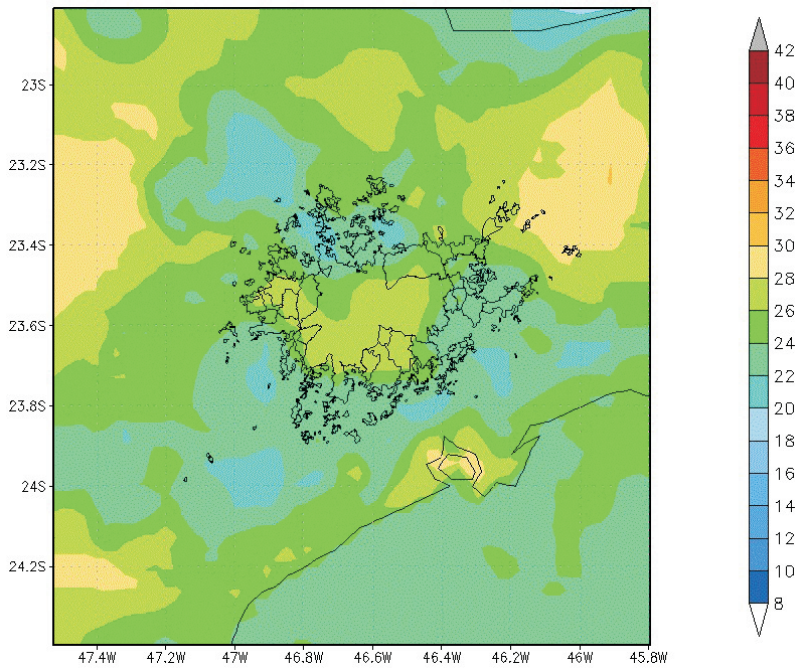

Figura 20 - Temperatura a dois metros do solo às 1800 UTC de 26/11/2014 no cenário padrão em ${ }^{\circ} \mathrm{C}$. pela formação das nuvens e, consequentemente, da precipitação.

Considerando o tipo e uso do solo padrão, o resultado numérico para a precipitação acumulada das 2100 UTC do dia 22 à 0000 UTC do dia 23 (Fig. 23), foi uma grande mancha de precipitação na maior parte da região de estudo, com totais acumulados em três horas variando entre $5 \mathrm{~mm} \mathrm{e}$ $25 \mathrm{~mm}$; uma faixa verde atravessando parte da região urbanizada, indicando chuva entre $35 \mathrm{~mm}$ e $40 \mathrm{~mm}$; três núcleos nas bordas da mancha urbana de intensidades entre $50 \mathrm{~mm}$ e $100 \mathrm{~mm}$. Além disso, ocorreu um núcleo com $35 \mathrm{~mm}$ em seu perímetro, aumentando gradualmente até $80 \mathrm{~mm}$ em direção ao seu centro, localizado mais ao norte na área urbanizada; e uma grande concentração de precipitação

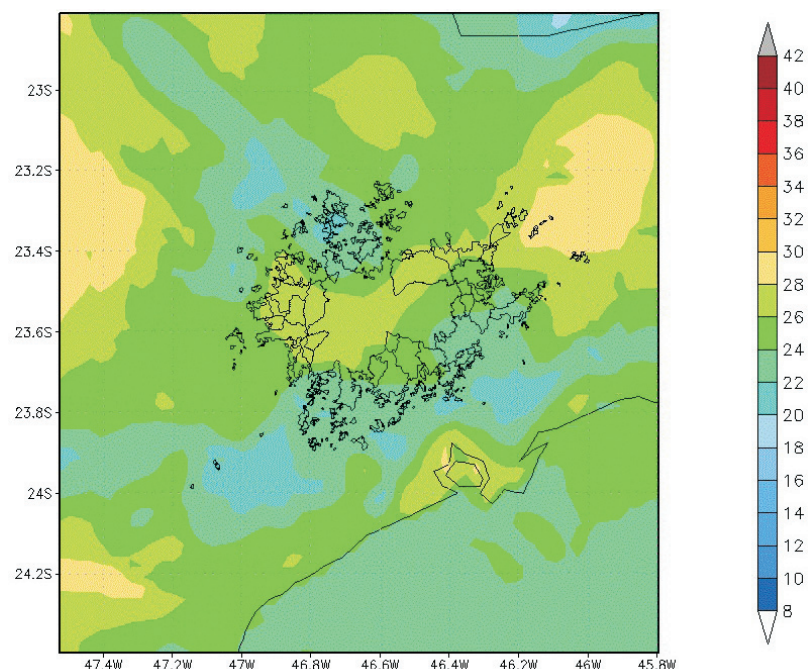

Figura 21 - Temperatura a dois metros do solo às 1800 UTC de 26/11/2014 no cenário urbanização ampliada em ${ }^{\circ} \mathrm{C}$ com parametrizações "cumulus" e "urbana" ativadas.

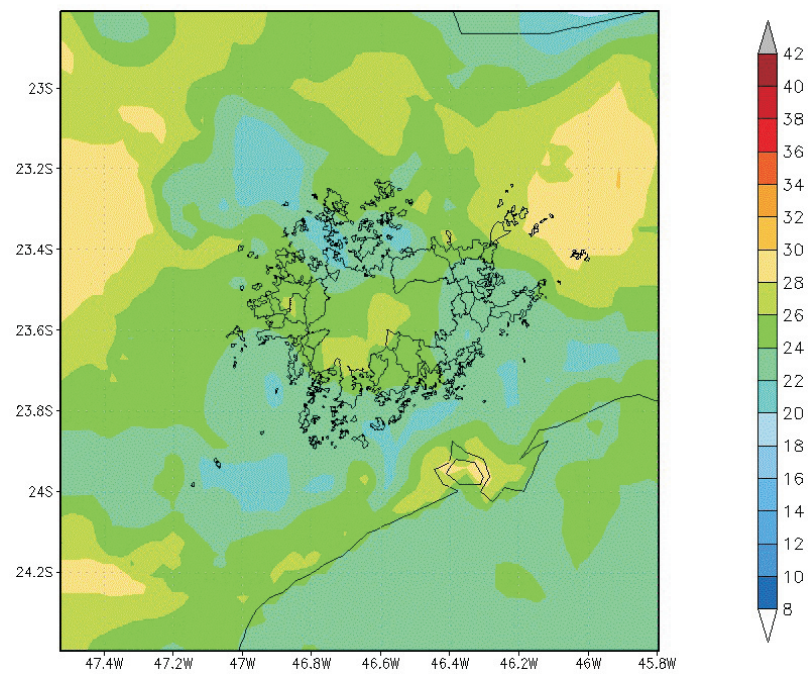

Figura 22 - Temperatura a dois metros do solo às 1800 UTC de 26/11/2014 no cenário floresta em ${ }^{\circ} \mathrm{C}$. 

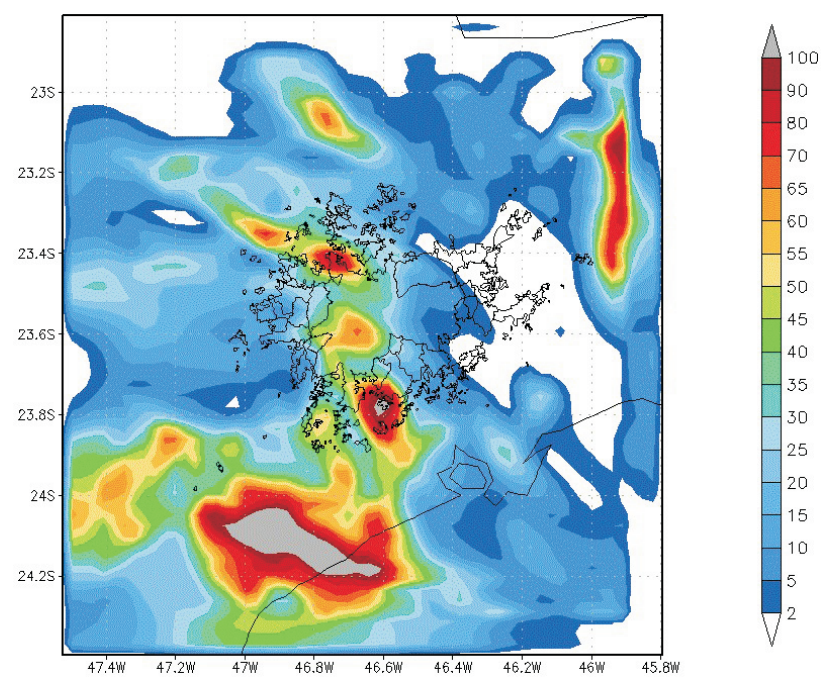

Figura 23 - Precipitação de acumulada das 2100 UTC de 22/12/2014 à 0000 UTC de 23/12/2014 no cenário padrão em mm.

variando de $35 \mathrm{~mm}$ a mais do que $100 \mathrm{~mm}$ à sudoeste da mancha urbana.

Com a alteração do tipo e do uso do solo de padrão para floresta, percebeu-se que os resultados foram similares em relação ao cenário anterior (Fig. 24), exceto pela diminuição da chuva no interior da região urbanizada e a intensificação da precipitação do núcleo na borda sul da área urbanizada. Já com a alteração do tipo e uso do solo de padrão para "mais urbanizado", a principal diferença encontrada foi a intensificação do núcleo de chuva localizado na borda oeste central da mancha urbana (Fig. 25).

Como não foram visualizadas grandes alterações no comportamento da variável precipitação nos três cenários, percebe-se que a presença ou ausência da região urbanizada teve uma menor influência nos padrões locais de precipitação nesta situação pré-frontal.
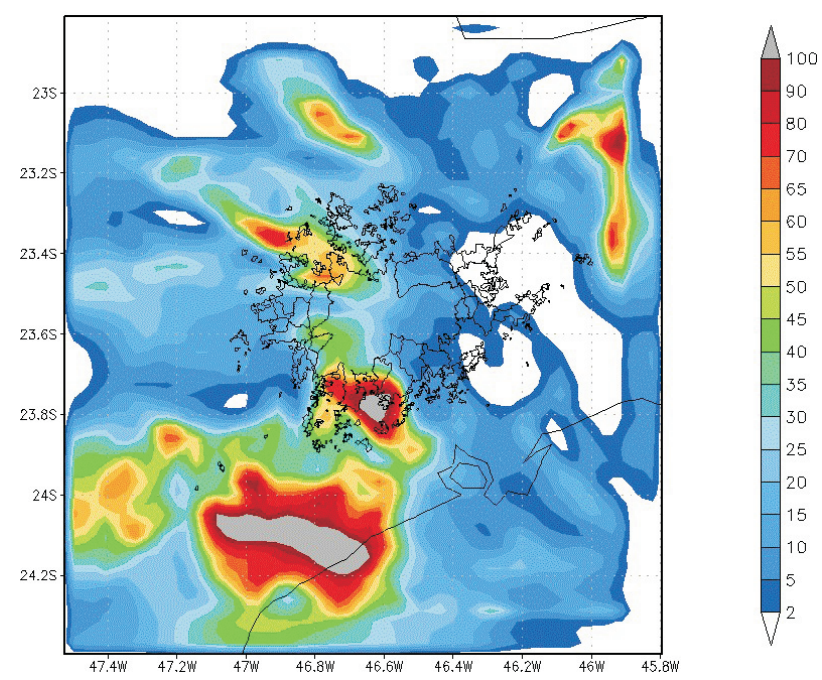

Figura 24 - Precipitação de acumulada das 2100 UTC de 22/12/2014 à 0000 UTC de 23/12/2014 no cenário floresta em mm.

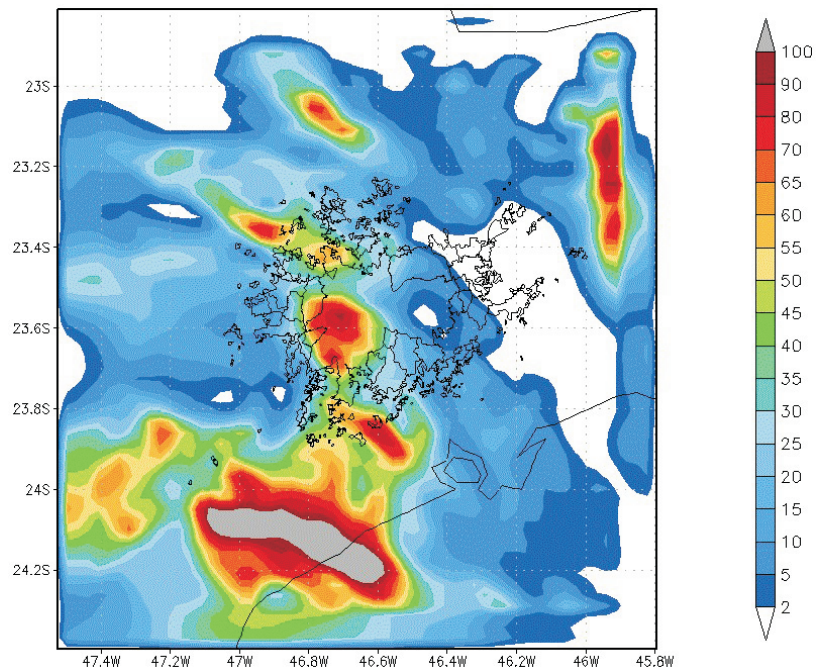

Figura 25 - Precipitação de acumulada das 2100 UTC de 22/12/2014 à 0000 UTC de 23/12/2014 no cenário urbanização ampliada em mm.

\subsubsection{Características fisicas dos processos de convecção associados com a mancha urbana}

Com base nos resultados, observa-se que a presença da urbanização da RMSP ocasiona uma diminuição da diferença relativa da umidade específica (Fig. 26 - sinalização vermelha) e um aumento expressivo dos fluxos de calor sensível no interior da área urbanizada (Fig. 27 sinalização preta), associado a um aumento da diferença relativa da umidade específica em seu entorno (Fig. 26 sinalização preta) e uma alteração dos movimentos verticais da atmosfera local, que se estendeu, em alguns casos, até as regiões adjacentes a mancha (Fig. 28 - sinalização vermelha).

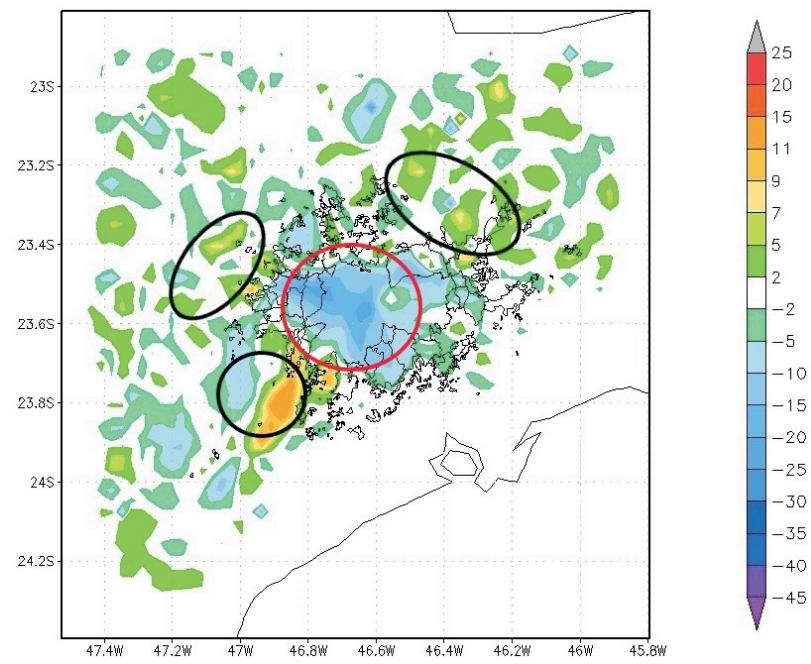

Figura 26 - Diferença relativa da umidade específica do ar às 1800 UTC de 25/01/2014 respectivamente entre os cenários padrão e floresta em unidade percentual, tomando como referência o cenário padrão. 

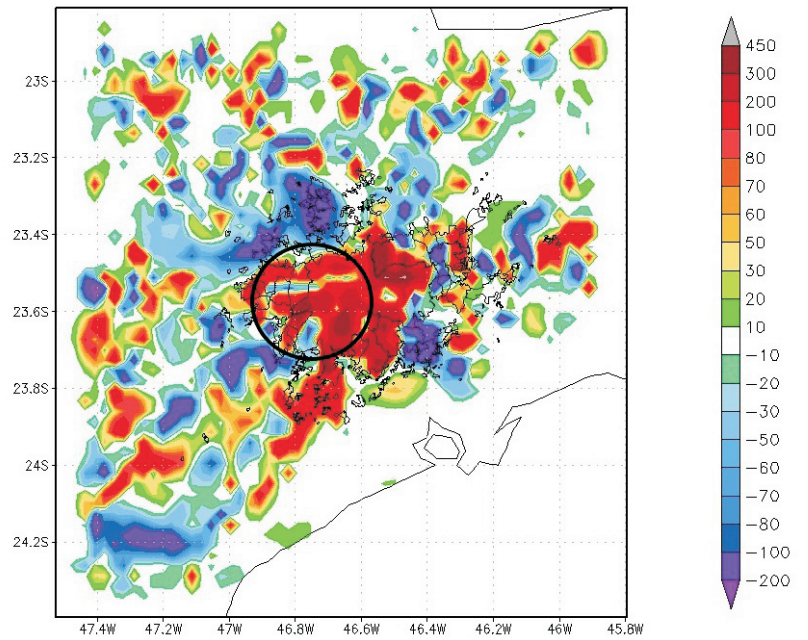

Figura 27 - Diferença do calor sensível às 1800 UTC de 25/01/2014 respectivamente entre os cenários padrão e floresta em W/m 2 .
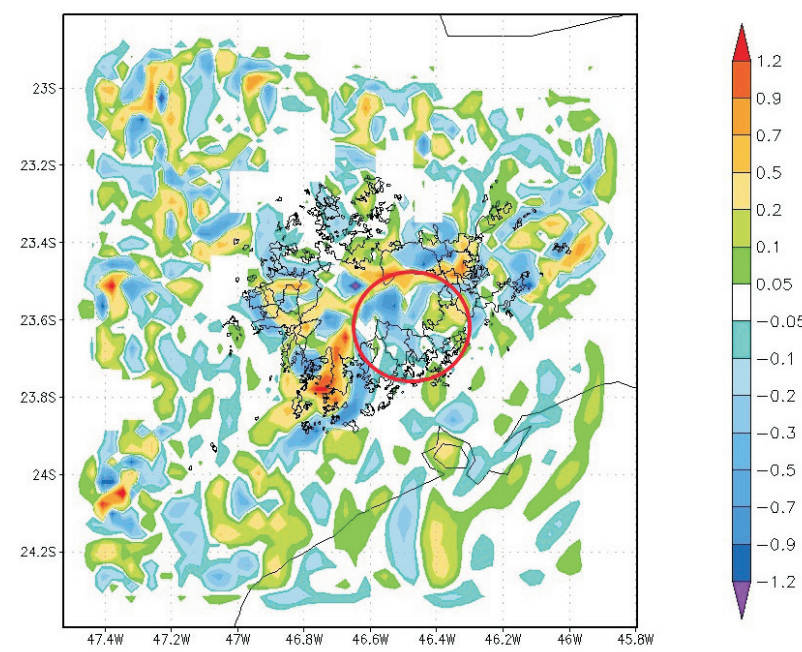

Figura 28 - Diferença do ômega às 1800 UTC de 25/01/2014 respectivamente entre os cenários padrão e floresta $\mathrm{em} \mathrm{hPa} / \mathrm{s}$.

No caso da mancha urbana ampliada, estes efeitos se intensificaram de tal forma que a umidade fica concentrada no entorno da mancha, não conseguindo ser advectada ao seu centro (Fig. 29 - sinalização vermelha), o que tende a concentrar a precipitação nesta região (Fig. 30 - sinalização vermelha), de forma que os núcleos de convecção não conseguem atingir o seu interior, diferentemente do que é observado com a mancha urbana padrão, onde os movimentos ascendentes conseguem suportar a convecção, mesmo no interior da mancha urbana, ocasionado totais de precipitação mais concentrados no cenário urbanizado do que em um cenário hipotético de floresta (Fig. 31).

Ressalta-se que o processo é complexo e algumas interações se mostraram bastante não-lineares, já que a urbanização, aumenta os fluxos de calor e os movimentos ascendentes na área urbana, no entanto, ocasiona uma dimi-

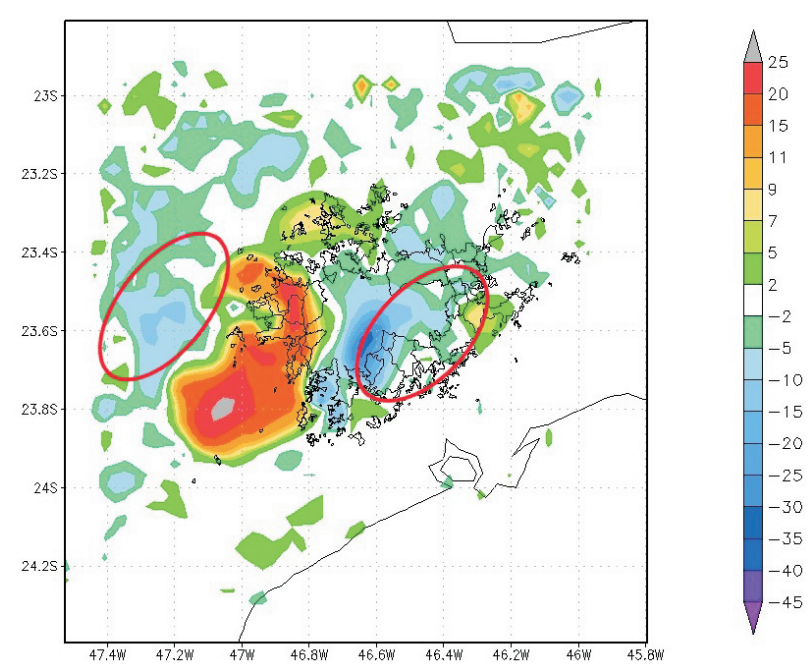

Figura 29 - Diferença relativa da umidade específica do ar às 2100 UTC de 25/01/2014 respectivamente entre os cenários urbanização ampliada e padrão em unidade percentual, tomando como referência o cenário urbanização ampliada.

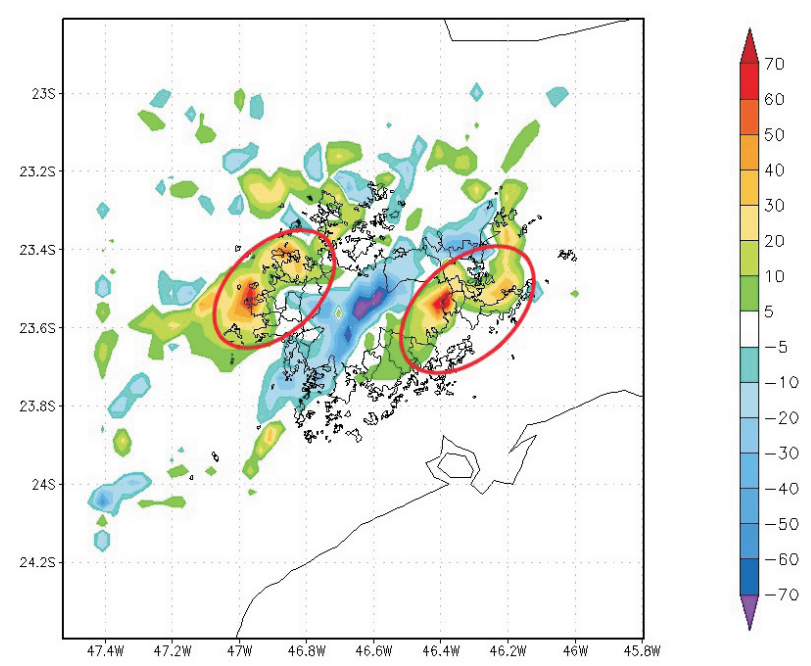

Figura 30 - Diferença da precipitação acumulada das 1800 UTC às 2100 UTC de 25/01/2014 respectivamente entre os cenários urbanização ampliada e padrão em mm.

nuição considerável da umidade na região, o que condiciona a ocorrência da precipitação, mesmo aquela de origem convectiva, à advecção de umidade proveniente do entorno da mancha.

\section{Conclusões}

As avaliações da série histórica de precipitação demonstraram indícios de mudanças nos padrões de precipitação da RMSP em dois períodos distintos: nas décadas de 1980 e 1990 e do ano 2000 até a atualidade. As mudanças observadas nas décadas de 1980 e 1990 podem estar associadas ao ENOS, que foram mais fortes e frequentes neste período. A partir da década de 2000 , o crescimento da 


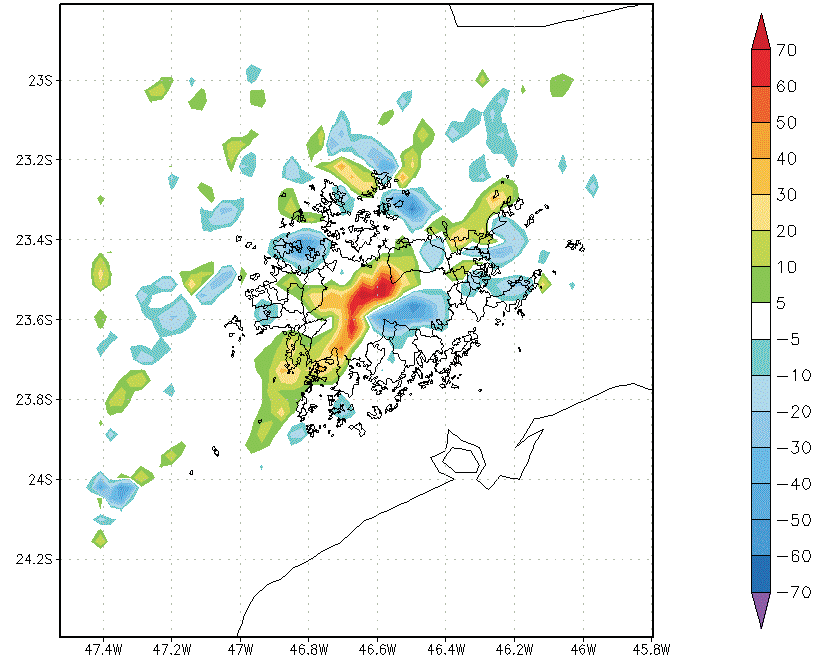

Figura 31 - Diferença da precipitação acumulada das 1800 UTC às 2100 UTC de 25/01/2014 respectivamente entre os cenários padrão e floresta em $\mathrm{mm}$.

urbanização da RMSP pode ser o evento mais significativo a ser relacionado à mudança de padrão, observando-se, neste período, um número menor de dias com chuva, mas uma frequência maior de eventos de precipitação intensa. É interessante notar que, apesar desta mudança de padrão, as médias de precipitação durante os meses de verão não apresentaram tendência significativa ao longo da série histórica, isso indica que a característica da precipitação na região é que tem mudado.

Para avaliar numericamente a hipótese da influência da urbanização na característica da precipitação da RMSP a partir do WRF, variou-se o tipo de cobertura do solo, a partir da criação de cenários com a urbanização padrão do modelo WRF, sem urbanização (somente floresta nativa) e presumindo um aumento da urbanização. Os resultados obtidos em dias específicos nos quais a convecção teve um papel determinante na formação da precipitação ressaltaram a forte influência da urbanização na dinâmica atmosférica e, consequentemente, na ICU da RMSP, culminando em eventos severos e concentrados de precipitação convectiva ao redor e no interior da região urbanizada. Nas simulações alterando a urbanização por floresta nativa a precipitação tendeu a ocorrer, na maioria das vezes, de forma mais distribuída e com núcleos de menor intensidade, exceto nas simulações reproduzindo uma situação pré-frontal, onde as instabilidades geradas por sistemas de maior escala se sobrepuseram aos efeitos convectivos locais, não sendo observadas diferenças significativas na modelagem dos três cenários.

\section{Referências}

ALVES, H.P.F.; ALVES, C.D.; PEREIRA, M.N.; MONTEIRO, A.M.V. Dinâmicas de urbanização na hiperperiferia da me- trópole de São Paulo. Revista Brasileira de Estudos de População, Rio de Janeiro, v. 27, n. 1, p. 141-159, 2010.

ANGELIS, C.F.; MACHADO, L.A.T.; MORALES, C.A.; SILVA, S.A.A.; HENRIQUES, C.R. et al.. Rede de radares meteorológicos: ação conjunta DECEA - INPE/CPTEC. In: Congresso Brasileiro de Meteorologia, 14., 2006, Florianópolis. Anais Florianópolis: Sociedade Brasileira de Meteorologia, 2006.

ARNDT, D.S.; BARINGER, M.O.; JOHNSON, M.R. (Ed.) State of the climate in 2009. Bull. Am. Met. Soc., v. 91, n. 7, 2010.

DIAS, M.A.F.S.; DIAS, J.; CARVALHO, L.M.V.; FREITAS, E.D.; DIAS, P.L.S. Changes in extreme daily rainfall for São Paulo, Brazil. Climatic Change, v. 116, n. 3-4, p. 705-722, 2013.

DUDHIA, J. Numerical study of convection observed during the Winter Monsoon Experiment using a mesoscale two-dimensional model. Journal of Atmospheric Sciences, v. 46, n. 20 , p. $3077-3107,1989$.

DYER, A.J.; HICKS, B.B. Flux-gradient relationships in the constant flux layer. Quarterly Journal Royal Meteorological Society, v. 96, n. 410, p. 715-721, 1970.

EZBER, Y.; SEN, O.L.; KINDAP, T.; KARACA, M. Climatic effects of urbanization in Istanbul: a statistical and modeling analysis. International Journal of Climatology, v. 27, n. 5, p. 667-679, 2007.

FREITAS, E.D.; DIAS, P.L.D. Alguns efeitos de áreas urbanas na geração de uma ilha de calor. Revista Brasileira de Meteorologia, v. 20, n. 3, p. 355-366, 2005.

GAMARRA, N.L.R.; CORRÊA, M.P.; TARGINO, A.C.L. Utilização de sensoriamento remoto em análises de albedo e temperatura de superfície em Londrina - PR: contribuições para estudos de ilha de calor urbana. Revista Brasileira de Meteorologia, v. 29, n. 4, p. 537-550, 2014.

GROSSMAN-CLARKE, S.; ZEHNDER, J.A.; STEFANOV, W.L.; LIU, Y.; ZOLDAK, M.A. Urban modifications in a mesoscale meteorological model and the effects on nearsurface variables in an arid metropolitan region. Journal of Applied Meteorology, v. 44, p. 1281-1297, 2005.

HONG, S.Y.; DUDHIA, J.; CHEN S.H. A revised approach to ice microphysical processes for the bulk parameterization of clouds and precipitation. Monthly Weather Review, v. 132, p. 103-120, 2004.

HONG, S.Y.; NOH Y.; DUDHIA, J.A. New vertical diffusion package with an explicit treatment of entrainment processes. Monthly Weather Review, v. 134, p. 2318-2341, 2006.

INSTITUTO BRASILEIRO DE GEOGRAFIA E ESTATÍSTICA (IBGE). Servidor de FTP. Disponível em: ftp://geoftp.ibge.gov.br/, acesso em: janeiro 2015.

INSTITUTO NACIONAL DE PESQUISAS ESPACIAIS (INPE). Centro de Previsão de Tempo e Estudos Climáticos (CPTEC). Divisão de Satélites e Sistemas Ambientais (DESA). Banco de dados e imagens. Disponível em: satelite.cptec.inpe.br, acesso em: janeiro 2015.

KAIN, J.S. The Kain-Fritsch convective parameterization: an update. Journal of Applied Meteorology, v. 43, p. 170-181, 2004.

LIN, S.; FENG, J.; WANG, J.; HU, Y. Modeling the contribution of long-term urbanization to temperature increase in three extensive urban agglomerations in China. Journal of Geo- 
physical Research: Atmospheres, v. 121, n. 4, p. $1683-$ 1697, 2016.

MIAO, S.; CHEN, F.; LI, Q.; FAN, S. Impacts of urbanization on a summer heavy rainfall in Beijing. In: International Conference on Urban Climate, 7., 2009, Yokohama, Japan. Anais Yokohama, Japan: Royal Meteorological Society, 2009.

MLAWER, E.J.; TAUBMAN, S.J.; BROWN, P.D.; IACONO, M.J.; CLOUGH, S.A. Radiative transfer for inhomogeneous atmospheres: RRTM, a validated correlated-k model for the longwave. Journal of Geophysical Research: Atmospheres, v. 102, p. 16663-16682, 1997.

NATIONAL CENTER FOR ATMOSPHERIC RESEARCH (NCAR). ARW version 3 modeling system user's guide, 2015. Disponível em: www.mmm.ucar.edu, acesso em: janeiro 2014.

OKE, T.R. Boundary layer climates. [S.1.]: Routledge, 1987. p. $262-303$

OKE, T.R.; JOHNSON, G.T.; STEYN, D.G.; WATSON, I.D. Simulation of surface urban heat islands under 'ideal' conditions at night. Part 2: diagnosis of causation. BoundaryLayer Meteorology, v. 56, p. 339-358, 1991.

OKE, T.R. The energetic basis of the urban heat island. Quarterly Journal of the Royal Meteorological Society, v. 108, p.124, 1982

OLIVEIRA, F.P.; OYAMA, M.D. Antecedent atmospheric conditions related to squall-line initiation over the northern coast of Brazil in july. Weather and Forecasting, v. 30, p. 1254-1264, 2015.

PAULSON, C.A. The mathematical representation of wind speed and temperature profiles in the unstable atmospheric surface layer. Journal of Applied Meteorology, v. 9, p. 857-861, 1970.

RAIMUNDO, C.C.; SANSIGOLO, C.A.; MOLION, L.C.B. Tendências das classes de precipitação na Região Metropolitana de São Paulo. Revista Brasileira de Meteorologia, v. 29, n. 3, p. 397-408, 2014.

REBOITA, M.S.; GAN, M.A.; ROCHA, R.P.; AMBRIZZI, T. Regimes de precipitação na América do Sul: uma revisão bibliográfica. Revista Brasileira de Meteorologia, v. 25, n. 2, p. 185-204, 2010.

ROCHA, A.M.G.C.; GANDU, A.W. A Zona de Convergência do Atlântico Sul. Climanálise, São José dos Campos, São Paulo, 1996.

SANT'ANNA NETO, J.L. Avaliação das mudanças no regime das chuvas do Estado de São Paulo durante um século (1888-1993). Acta Scientiarum, v. 21, n. 4, p. 915-921, 1999. Disponível em: www.periodicos.uem.br. Acesso em: janeiro 2015.

SATYAMURTY, P.; FERREIRA, C.C.; GAN, M.A. Cyclonic vortices over South America, Tellus, v. 42A, p. 194-201, 1990.

SCOLAR, J.; DIAS, M.A.F.S. Linhas de instabilidade pré-frontais e sua dependência de condições sinóticas. In: Congresso Brasileiro de Meteorologia, 2., 1982, Pelotas, Rio Grande do Sul. Anais... Pelotas: Sociedade Brasileira de Meteorologia, 1982.

SHASTRI, H.; PAUL, S.; GHOSH, S.; KARMAKAR, S. Impacts of urbanization on indian summer monsoon rainfall. Jour- nal of Geophysical Research: Atmospheres, v. 120, n. 2, p. 496-516, 2014.

SKAMAROCK, W.C.; KLEMP, J.B.; DUDHIA, J.; GILL, D.O.; BARKER D.M. et al.. A description of the advanced research WRF Version 2 (No. NCAR/TN-468+ STR). National Center for Atmospheric Research, Boulder, CO, Mesoscale and Microscale Meteorology Div., 2008.

TEWARI, M.; CHEN, F.; WANG, W.; DUDHIA, J.; LEMONE, M.A. et al. Implementation and verification of the unified NOAH land surface model in the WRF model. In: Conference on Weather Analysis and Forecasting, 20. / Conference on Numerical Weather Prediction, 16., 2004, Seatle, Washington, Estados Unidos da América. Anais Seatle, Washington, Estados Unidos da América: American Meteorological Society, 2004. p. 11-15.

UNITED NATIONS, Department of Economic and Social Affairs, Population Division. World urbanization prospects: the 2014 revision: highlights (ST/ESA/SER.A/366), 2014. Disponível em: https://esa.un.org/unpd/wup/publications/files/wup2014-highlights.Pdf, acesso em: janeiro 2015.

UNIVERSIDADE DE SÃO PAULO (USP). Estação Meteorológica do Instituto de Astronomia, Geofísica e Ciências Atmosféricas (IAG). São Paulo, 2015. Disponível em: www.estacao.iag.usp.br, acesso em: janeiro 2015.

VIEIRA, S.O.; OLIVEIRA, N.V.; SATYAMURTY, P.; ANDREOLI, R.V. Aplicação do método fuzzy na classificação da zona de convergência do atlântico sul da Amazônia. Revista Brasileira de Meteorologia, v. 29, n. 4. p. 621-631, 2014.

VOOGT, J.A.; OKE, T.R. Thermal remote sensing of urban climates. Remote Sensing of Environment, v. 86, p. 370-384, 2003.

WEBB, E.K. Profile relationships: The log-linear range, and extension to strong stability. Quarterly Journal Royal Meteorological Society, v. 96, p. 67-90, 1970.

XAVIER, T.M.B.S.; XAVIER, A.F.S.; DIAS, M.A.F.S. Evolução da precipitação diária num ambiente urbano: o caso da cidade de São Paulo. Revista Brasileira de Meteorologia, v. 9, n. 1, p. 44-53, 1994.

YU, M.; LIU, Y. The possible impact of urbanization on a heavy rainfall event in Beijing. Journal of Geophysical Research: Atmospheres, v. 120, n. 16, p. 8132-8143, 2015.

ZHANG, C.; CHEN, F.; MIAO, S.; LI, Q.; XUAN, C. Influences of urbanization on precipitation and water resources in the metropolitan Beijing area. In: Conference on Hydrology, 21., San Antonio, Texas, Estados Unidos da América. Anais San Antonio, Texas, Estados Unidos da América: American Meteorological Society, 2007.

ZHANG, D.L.; ANTHES, R.A. A high-resolution model of the planetary boundary layer- sensitivity tests and comparisons with SESAME-79 data. Journal of Applied Meteorology, v. 21, p. 1594-1609, 1982.

\section{Endereço de Internet}

United States Geological Survey (USGS): http://www.usgs.gov/.

This is an Open Access article distributed under the terms of the Creative Commons Attribution Non-Commercial License which permits unrestricted non-commercial use, distribution, and reproduction in any medium provided the original work is properly cited. 